\title{
Morfologia urbana como um campo interdisciplinar emergente
}

\author{
Anne Vernez Moudon \\ College of Architecture and Urban Planning, University of Washington, Seattle, WA \\ 98195, USA. E-mail: moudon@u.washington.edu
}

Artigo originalmente publicado na Urban Morphology em Outubro de 1997

\begin{abstract}
Resumo. Neste artigo identificam-se as forças e os acontecimentos que conduziram à formação do International Seminar on Urban Form (ISUF). $O$ ISUF tem vindo a expandir o campo da morfologia urbana para além dos seus limites originais na área da geografia particularmente em direção aos domínios da arquitetura e do planeamento. Três escolas de morfologia urbana, em Inglaterra, Itália e França, têm vindo a desenvolver um processo de aproximação, seguindo o trabalho seminal de dois morfologistas, $M . R$. G. Conzen e Saverio Muratori. A aproximação destas escolas fornece as bases para a definição de um campo interdisciplinar e a oportunidade de estabelecer fundações teóricas comuns para um conjunto crescente de morfologistas em diferentes partes do mundo. A ambiciosa missão do ISUF é abordar um conjunto de temas atuais e concretos relacionados com o processo de construção da cidade, fornecendo um fórum de reflexão e ação que inclui disciplinas, e profissões relacionadas, provenientes de diferentes culturas. Neste artigo discute-se o potencial de um campo interdisciplinar de morfologia urbana e o seu contributo para a compreensão e para a gestão dos processos de desenvolvimento urbano num período de transformação sem precedentes.
\end{abstract}

Palavras-chave: morfologia urbana, interdisciplinaridade, construção da cidade, geografia, arquitetura

Morfologia urbana é o estudo da cidade como habitat humano. O etnógrafo LéviStrauss (1954, pp.137-8) descreveu a cidade como 'a mais complexa das invenções humanas,...na confluência entre natureza e artefacto'. Os morfologistas analisam a evolução da cidade desde o seu assentamento até às subsequentes transformações, identificando e dissecando os seus vários componentes. A cidade resulta da acumulação e da integração de muitas ações individuais, ou de pequenos grupos - ações determinadas por tradições culturais e moldadas por forças sociais e económicas desenvolvidas ao longo do tempo.

Os morfologistas centram-se nos resultados tangíveis das forças sociais e económicas: estudam a concretização de ideias e intenções à medida que estas tomam forma sobre o solo moldando as nossas cidades. Edifícios, jardins, ruas, parques e monumentos, estão entre os principais elementos da análise morfológica. No entanto, estes elementos são considerados organismos que vão sendo constantemente utilizados e transformados ao longo do tempo. Estes elementos também existem num estado de inter-relação próxima e dinâmica: estruturas construídas que moldam e que são moldadas pelos espaços abertos à sua volta; ruas de carácter público servindo e sendo utilizadas por proprietários de parcelas privadas dispostas ao longo dessas ruas. O estado dinâmico da cidade, e a relação próxima dos seus elementos, levou a que muitos morfologistas preferissem o termo 'morfogénese urbana' para descrever o seu campo de estudo. 
No verão de 1996, um grupo de morfologistas com formações diversas incluindo arquitetura, geografia, história e planeamento, formalizaram o International Seminar on Urban Form (ISUF - ou SIFU, Séminaire International de la Forme Urbaine, Seminario Internazzionale de la Forma Urbana). O grupo, que incluía investigadores de Inglaterra, França, Alemanha, Irlanda, Suíça, Japão e EUA tinha-se reunido nos dois verões anteriores no mesmo local, Lausanne, Suíça, para explicar e comparar o seu trabalho. Estes encontros reconheceram a expansão da morfologia urbana para além dos seus limites originais na geografia, e a sua emergência como um campo interdisciplinar. Os encontros sublinharam a necessidade de promover um diálogo internacional e de investigar o âmbito das bases teóricas deste campo.

\section{Três escolas de morfologia urbana}

As reuniões do ISUF vieram a confirmar que diversas gerações de académicos tinham estado ativas no campo da morfologia urbana, não apenas em Inglaterra, mas também em Itália e em França, e que muitos investigadores, a título individual, numa variedade de outros países, estavam também a contribuir para o seu desenvolvimento. Dois indivíduos figuram de modo proeminente como investigadores pioneiros neste campo: M. R. G. Conzen a um geógrafo Alemão que emigrou para Inglaterra antes da Segunda Guerra Mundial, inicialmente para estudar e exercer a atividade de planeamento urbano, e depois para ensinar geografia; e Saverio Muratori (1910-1973), um arquiteto Italiano que lecionou primeiro em Veneza e depois em Roma. Ambos eram homens excecionais e não conformados nos seus domínios, a geografia e a arquitetura, respetivamente. Conzen, que é mais conhecido pelo seu estudo detalhado sobre Alnwick (1960), teve de conviver com a revolução quantitativa da geografia, no pósguerra, que em larga medida passou por cima da sua investigação indutiva e empírica, alegadamente pouco rigorosa e com pouca capacidade preditiva. Por outro lado, Muratori que usava as suas 'histórias operativas' de Veneza e Roma (Muratori, 1959, 1963) como as bases teóricas para as suas aulas de desenho arquitetónico, sofreu um isolamento e uma desconsideração intelectual por parte dos seus colegas modernistas na arquitetura.

No entanto, a força dos ensinamentos de Conzen e Muratori atraiu seguidores que perceberam a importância de capturar aquilo que os mestres chamavam de genius loci e as singulares capacidades mnemônicas da cidade enquanto palimpsesto cultural. J. W. R. Whitehand (1981) assegurou o legado de Conzen ao compilar alguns dos seus trabalhos e ao investigar o significado e o desenvolvimento das suas ideias. Whitehand, um académico da geografia histórica e urbana, alargou os limites da morfologia até à economia urbana, ao investigar a relação entre a cidade, os seus habitantes, e as dinâmicas da indústria de construção. Em 1974, Whitehand formou o Urban Morphology Research Group na University of Birmingham, que inclui investigação sobre cidades medievais, nomeadamente a pesquisa conduzida por T. R. Slater, bem como estudos sobre a expansão e a transformação suburbana do século XX. Um programa sustentado de conferências e publicações, desenvolvido ao longo dos últimos 25 anos, tornou o Urban Morphology Research Group num centro de investigação de exceção, complementando as principais tradições em morfologia urbana. Um fluxo constante de distintos doutorados de Birmingham, como Peter Larkham, Karl Kropf e Keith Lilley, ajudou a disseminar a influência do grupo.

Em Itália, Gianfranco Caniggia (1933-87) assumiu a tradição de Muratori, que tinha orientado o seu estudo de 1963 sobre a cidade de Como. Na sua prática de ensino e nas suas publicações, Caniggia continuou a tradição Muratoriana que ele chamou 'processual tipológica' devido ao enfoque nos tipos edificados enquanto raiz elementar da forma urbana. Como Muratori, Caniggia colocou a sua teoria em prática, permanecendo ativamente envolvido como arquiteto ao longo da sua vida. A sua investigação estendeu-se a diferentes cidades em Itália e no Norte de Africa, sendo conduzida com colegas e estudantes que 
prolongaram o legado de Muratori. Atualmente, Giancarlo Cataldi, Gian Luigi Maffei, Maria Grazia Corsini, Paolo Maretto, Giuseppe Strappa, entre outros, continuam a tradição em Florença, Roma, Génova e Siena.

Depois de Conzen e Muratori lançarem as bases para as duas escolas anteriores, uma terceira escola emergiu em França no final dos anos 60, quando os arquitetos Philippe Panerai e Jean Castex, juntamente com o sociólogo Jean-Charles Depaule, fundaram a Escola de Arquitetura de Versalhes como parte do processo de separação das BelasArtes. Do mesmo modo que a Escola Italiana, também a Escola Francesa emergiu como reação à arquitetura modernista e à sua rejeição da história. A escola beneficiou ainda do vibrante debate intelectual sobre a vida urbana que então atravessava a arquitetura envolvendo críticos proeminentes como o sociólogo Henri Lefebvre e o historiador André Chastel.

Quando já estavam envolvidos na investigação sobre a evolução histórica dos bairros parisienses, Panerai e Castex descobriram as obras de Muratori, então desconhecidas em França, que forneceram o ímpeto para o aprofundamento das dimensões teórica e metodológica do seu trabalho. Ao longo dos anos, estabeleceram contactos com investigadores não apenas em Itália, mas também em Espanha e na América Latina. O resultado deste diálogo continua por documentar. Por outro lado, as anteriores publicações de Castex e Panerai exerceram uma considerável influência por toda a comunidade de arquitetos na Europa. Os subsequentes estudos detalhados sobre a cidade de Versalhes, as bastides Francesas, e a cidade do Cairo, no Egipto, ajudaram a preparar uma segunda geração de morfologistas em França. Ao longo da última década fundaram-se grupos de investigação em Nantes, por Michael Darin, e em Marselha, por Lucien Bonillo.

\section{ISUF: uma geneologia}

Até à primeira reunião do ISUF em 1994, tinha havido alguma promoção individual, mas poucas trocas e ligações formais entre as três principais escolas de morfologia urbana - Conzeniana, Muratoriana e Versalhesi. A criação do ISUF foi conduzida por um conjunto de contactos pessoais e circunstanciais particulares, bem como pela convergência fortuita de duas tentativas isoladas de promoção e cobertura internacional: a sistemática disseminação de publicações por parte dos geógrafos de língua Inglesa e a crescente popularidade global da arquitetura Italiana.

O grupo Conzeniano manteve um perfil consistente nos círculos geográficos Britânico e Americano, beneficiando internacionalmente da participação ativa do filho de Conzen, M. P. Conzen, um geógrafo da University of Chicago; e de contactos continuados com James Vance $\mathrm{Jr}$ na University of California, Berkley, e com Deryck Holdsworth, agora na Pennsylvania State University. O grupo de Birmingham estabeleceu também ligações com investigadores na Irlanda, Alemanha, Polónia, Espanha e Áustria. A tradição Stadtlandschaft, com uma grande força na geografia da Europa Central no período entre guerras, incluindo na University of Berlin onde Conzen tinha estudado, continuou a ter os seus seguidores. Mas nos anos 80, o número destes seguidores tinha encolhido restando, comparativamente, poucos académicos, como Elisabeth Lichtenberger e Dietrich Denecke, que permaneceram ativos neste campo ii.

O grupo de Birmingham desenvolveu também laços com a prática profissional de planeamento Britânica, particularmente na área da conservação urbana e património, um interesse diretamente relacionado com as ideias de Conzen sobre gestão da paisagem urbana. Pelo contrário, os contactos com arquitetos emergiram de forma lenta e, ironicamente, foram-se consolidando à medida que os arquitetos Britânicos se foram familiarizando com a Escola Muratoriana em meados dos anos 80 .

A difusão das ideias Muratorianas seguiu o aumento da popularidade da arquitetura Italiana por todo o mundo, particularmente com a tradução para Inglês dos trabalhos de Aldo Rossi nos anos 80 iii. Apesar de Rossi ter escolhido não assumir a influência de Muratori na fase inicial da sua prática 
profissional, a verdade é que acabou por promover, com sucesso, o retorno aos tipos edificados tradicionais, potenciando assim um renovado interesse pela cidade histórica e promovendo o seu significado na arquitetura. A mensagem de Rossi teve eco nos arquitetos Britânicos, Americanos e Franceses. Estes arquitetos leram também os textos de outro arquiteto Italiano, Carlo Aymonino, cujo estudo sobre Pádua e outros textos que ele designou como 'tipomorfologia' estimularam o interesse pelo desenho da cidade. Incidentalmente, mas com significado para a estrutura do ISUF, Rossi e Aymonino vieram a rejeitar a morfologia urbana, vendo-a como um campo que promovia soluções ultrapassadas para os atuais problemas urbanos e como impotente na resolução de um conjunto de temas da arquitetura moderna.

No entanto, em retrospetiva, o contributo italiano com um carácter mais instrumental na ligação das três principais escolas de morfologia urbana e na criação do ISUF, foi o programa de reabilitação do centro histórico de Bolonha, que teve Caniggia como consultor. A rápida difusão deste projeto, o seu interessante âmbito e o sucesso da sua implementação, ajudou a desenvolver contactos entre morfologistas em diferentes partes do mundo.

Foi neste contexto que Caniggia foi convidado para visitar o Oxford Polytechnic pelo arquiteto e Italianófilo Ivor Samuels no início dos anos 80. Apesar de Caniggia não ter encontrado os geógrafos de Birmingham por altura desta visita, Samuels tinha então começado a colaborar com os seus compatriotas. Nos últimos anos de vida, Caniggia desenvolveu um extensivo e abrangente programa. Caniggia passou três meses na University of Washington, em Seattle, em 1986, após um encontro comigo e com um dos meus colegas, no ano anterior em Nápoles, Itália, num seminário em homenagem ao trabalho de Kevin Lynch. Caniggia visitou ainda o Federal Polytechnic Institute of Zurich, na Suíça, para apresentar o seu trabalho (em co-autoria com Maffei) sobre Florença que foi traduzido e editado por Sylvain Malfroy.

Como mencionado anteriormente, a Escola de Versalhes manteve contactos nos mundos Latino e Árabe. No final da década de 1970, o seu trabalho tinha sido traduzido para várias línguas europeias e circulava nos Estados Unidos para uma possível publicação em Inglês - esta tentativa falhou e, até à data, este trabalho não está acessível a audiências de língua inglesa $\mathrm{e}$. A afirmação internacional dos franceses, na morfologia urbana, deu-se pela primeira vez em 1986 através do prestigiado Institut d'Urbanisme da Universidade de Paris. O Instituto organizou um simpósio sobre morfologia urbana abordando a questão do fracasso do modernismo no desenho da nova cidade. A lista de convidados incluiu muitos académicos, planeadores e arquitetos de renome, da Europa e América do Norte. No entanto, nem os membros da Escola de Versalhes, nem qualquer um dos colaboradores mais próximos das escolas de Birmingham e Muratoriana participaram no simpósio, à exceção de Ivor Samuels, do Oxford Polytechnic, e Albert Levy, que então lecionava em Genebra, na Suíça. No entanto, pouco depois do simpósio, estabeleceram-se ligações entre a Escola de Versalhes e o Institut d'Urbanisme, para o estudo da região parisiense, conduzindo Castex e Panerai a lecionar no Instituto. Também a nova geração de geógrafos urbanos franceses tem vindo a desenvolver relações de trabalho mais estreitas.

Castex, que havia passado uma temporada em Nova Iorque no final dos anos 1960, ajudou a reforçar o desenvolvimento de laços com a América do Norte, ao retornar em 1988, como Professor Visitante à University of Oregon. Lecionou também nessa altura, na University of Washington, em Seattle. Eu tinha conhecido Castex e visitado Versalhes um ano antes, embora conhecesse o seu trabalho (e de Panerai) há uma década, tendo partilhado pensamentos sobre morfologia com Francófilos como M. Christine Boyer e o académico da paisagem urbana Paul Groth, estudante de James Vance. Em 1987, eu tinha planeado dar uma palestra em Roma, como parte de uma tentativa de 'fechar o círculo' entre as escolas Italiana e Francesa de morfologia urbana. A súbita morte de Caniggia foi um impulso para estabelecer relações com os seus colegas em Florença, Roma e Génova. 
A promoção e o alcance no mundo de língua inglesa foram facilitados pela publicação da Urban Morphology Newsletter, do grupo de Birmingham, a partir de 1987. Em 1990, o grupo organizou uma conferência internacional e editou um livro reunindo contributos de vários NorteAmericanos e Europeus 'continentais'. Finalmente, têm vindo a desenvolver-se contactos individuais entre investigadores Norte-Americanos, Asiáticos e Australianos desde o final dos anos 80.

A genealogia do ISUF é, como seria expectável, complexa. No entanto, dada a fratura natural entre geografia e arquitetura, com as suas diferentes missões e intenções, as habituais disputas territoriais e, mais importante, dado o fosso cultural e linguístico entre Anglo-Saxónicos e Latinos, é uma feliz surpresa poder ver a criação do ISUF apenas quatro décadas depois da publicação da Storia Operante di Venezia de Muratori e de Alnwick de Conzen. Curiosamente, a neutralidade e centralidade geográfica - não por acaso - foi chamada para as três primeiras reuniões do ISUF que tiveram lugar na Suíça. Até então, académicos e investigadores Suíços tinham, de um modo natural, desenvolvido laços com as escolas de morfologia Italiana e Francesa. Léopolde Veuve, Bruno Marchand e Sylvain Malfroy ofereceram-se para acolher reuniões, em três anos consecutivos, na Federal Polytechnic School of Lausanne, que culminaram com a confirmação do ISUF como organização, o anúncio de uma primeira conferência aberta em Birmingham em 1997, e a criação da revista Urban Morphology.

Os primeiros encontros do ISUF em Lausanne incrementaram a intensidade das trocas entre as escolas. Mais especificamente, Attilio Petruccioli, que estudou sob o enquadramento da Escola Muratoriana em Itália, organizou conferências anuais em Cambridge, Massachusetts, desde 1995 sob os auspícios do MIT Aga Khan Program, nas quais participaram muitos dos membros da comunidade do ISUF. Em resultado, uma nova geração de morfologistas está a emergir rapidamente e a produzir trabalho comparativo sobre as três escolas.

\section{As bases teóricas}

Esta convergência de investigadores de diferentes disciplinas e áreas linguísticas assenta sobre uma base comum. Primeiro, é consensual que a cidade pode ser 'lida' e analisada através da sua forma física. Para além disso, existe um amplo reconhecimento de que, no seu nível mais elementar, a análise morfológica é baseada em três princípios.

i. A forma urbana é definida por três elementos físicos fundamentais: edifícios e os espaços abertos relacionados com estes, parcelas ou lotes, e ruas.

ii. A forma urbana pode ser compreendida em diferentes níveis de resolução. Normalmente, reconhecem-se quatro níveis, que correspondem ao edifício/parcela, à rua/quarteirão, à cidade, e à região.

iii. A forma urbana só pode ser compreendida na sua dimensão histórica uma vez que os elementos que ela compreende sofrem uma contínua transformação e substituição.

Assim, a forma, a resolução e o tempo constituem as três componentes fundamentais da investigação em morfologia urbana. Estas componentes estão presentes em todos os estudos, quer sejam desenvolvidos por geógrafos ou por arquitetos, quer se centrem na cidade medieval, barroca ou contemporânea. Reconhece-se que a mais pequena célula da cidade é constituída pela combinação dos seguintes elementos: a parcela de solo individual, juntamente com o seu edifício ou edifícios e com os espaços abertos. As características da célula definem a configuração e a densidade da forma urbana, bem como a sua utilização efetiva ou potencial ao longo do tempo. Estudos mostram que os atributos da célula e dos seus elementos refletem não apenas um período de tempo na história, mas também as condições socioeconómicas presentes no momento de desenvolvimento inicial. Ao longo do tempo, esses elementos são utilizados de forma diferente - por exemplo, por diferentes classes sociais transformados fisicamente, eliminados ou substituídos por novas formas. O ritmo de transformação, quer da função quer da forma 
das células, varia de cidade para cidade, mas também se enquadra, de um modo geral, em ciclos relacionados com a economia e a cultura. Os ciclos de construção e de transformação são processos importantes que devem ser explorados pelo planeamento urbano e pelo imobiliário; no entanto, raramente são estudados nas cidades contemporâneas.

Alguns estudos também se focam no que Conzen chama 'unidade de plano' e que os Italianos designam por 'tecido'. Unidades de plano ou tecidos são conjuntos de edifícios, espaços abertos, parcelas e ruas, que formam um todo coeso, ou porque foram todos construídos num mesmo tempo ou com as mesmas condicionantes, ou porque sofreram um mesmo processo de transformação.

Para além disso, e se bem que todas as análises morfológicas são desenvolvidas com um objetivo de construção de teoria, existem propósitos distintos entre as diferentes tradições em morfologia urbana que produzem diferentes tipos de teorias. Cada uma das três escolas tem tido diferentes intenções nos seus esforços de 'construção de teoria'. Essas intenções são as que se seguem:

i. O estudo da forma urbana com propósitos 'descritivos' e 'explicativos', com o objetivo de desenvolver uma 'teoria de construção da cidade' (théorie de l'édification de la ville). Estes estudos estão preocupados com o modo como as cidades são construídas e com o porquê. Este é o objetivo principal dos geógrafos, e da Escola de Birmingham em particular. Os cientistas sociais da Escola Francesa também têm este propósito quando desenvolvem estudos morfológicos.

ii. O estudo da forma urbana com propósitos 'prescritivos', com o objetivo de desenvolver uma 'teoria de desenho da cidade'. Estes estudos centram-se no modo como as cidades deveriam ser construídas. Este é o enfoque principal da Escola Italiana que deu a este propósito uma direção particular, o desenvolvimento de uma teoria de desenho do edificado assente nas tradições históricas de construção da cidade. Alguns investigadores Franceses têm tido intenções semelhantes nas suas análises morfológicas, tendo como propósito do seu trabalho o desenvolvimento de uma théorie du projet basée sur les traditions d'édification de la ville.

iii. O estudo da forma urbana para avaliar o 'impacto de teorias de desenho do passado na construção da cidade'. Este é o domínio da crítica de desenho, que faz a sofisticada distinção entre 'teoria do desenho como ideia' e 'teoria do desenho como prática'. Estes estudos avaliam as diferenças ou semelhanças entre diretivas sobre o que deve ser construído (teorias normativas) e aquilo que é realmente construído. A Escola Francesa tem defendido esta utilização da análise morfológica identificando, com sucesso, as raízes do modernismo no desenho urbano no século XVIII. No entanto, este continua a ser um exercício mental difícil para muitos planeadores, que tendem a não perder tempo a avaliar o impacto das suas ações sobre a vida (em termos de longo prazo) das cidades.

\section{Questões e potencial}

Como é frequente quando algo novo está a ser proposto, os pontos fortes da inovação são também as suas fraquezas. A fundação de um campo interdisciplinar de morfologia urbana cria tensões e oportunidades que o ISUF terá de enfrentar. Discutamos primeiro algumas das questões gerais relacionadas com a morfologia urbana e, em seguida, algumas das questões específicas sobre o estado atual do campo.

A missão do ISUF é ambiciosa e, portanto, cheia de potenciais conflitos com as estruturas existentes nos mundos da investigação e da prática. $O$ ISUF estabeleceu um domínio que se estende pela geografia, história, arqueologia, arquitetura e planeamento, e consequentemente pelas humanidades, ciências sociais e por um conjunto de profissões; estende-se pelo estudo e pela ação, pelo conhecimento e pela decisão, pela descrição e pela prescrição. Este domínio é atualmente constituído por um vasto mosaico de territórios intelectuais, ajustando lentamente os seus limites por entre as habituais disputas sobre poder e ideias, sendo tudo isto representado em inúmeras revistas, jornais, livros, organizações com as suas conferências associadas, páginas web, etc. Do lado 
positivo, o ISUF está a criar um domínio que reúne peças de todos estes territórios para se focar num fenómeno real: James Vance designa este fenómeno real como 'construção da cidade', de modo a incluir as formas físicas e todos os processos relacionados com o ato de fazer cidade. Isto significa que a morfologia urbana pode virar costas às lutas internas pelo poder que estão a ocorrer dentro da geografia e transcender as contendas adolescentes que assolam o planeamento, a arquitetura, o imobiliário e a construção. Significa ainda que a morfologia urbana poderá preencher um vazio que atualmente debilita tanto a investigação como a prática de 'construção da cidade'. Consequentemente, o ISUF é uma oportunidade para estabelecer um fórum de pensamento e ação sobre como moldar e gerir os nossos habitats - um assunto oportuno neste momento da história da civilização. Todavia, por mais excitante que seja a oportunidade e por mais nobre que seja o objetivo, o caminho futuro do ISUF será provavelmente árduo, por um conjunto de razões.

Primeiro, ao contrário, por exemplo, da engenharia e da medicina, a arquitetura e o planeamento têm ainda que desenvolver, isoladamente ou em conjunto, uma base de conhecimento partilhada. Ambas são profissões que prosperam na ação e no projetar de futuros possíveis, mas que deixam pouco espaço para a investigação e para a avaliação. São profissões que não seguiram outras no desenvolvimento de uma abordagem sistemática e empírica de aprendizagem e construção de uma base de conhecimento. São profissões que têm poucos - se é que têm algum - mecanismos para relacionar estudo e ação. Quaisquer que sejam as razões para a existência de uma abordagem artística no que se refere à tomada de decisão em arquitetura e planeamento, este estado de coisas significa que os morfologistas irão percorrer, com estas profissões, territórios desconhecidos, tendo de captar a atenção destas profissões, para demonstrar a validade e a eficácia da abordagem morfológica na identificação de relações de causa-efeito.

Do ponto de vista das ciências sociais, as dúvidas sobre as capacidades de construção de teoria por parte da morfologia urbana vêm de dois lados opostos. Por um lado, os positivistas questionam o modo empírico e indutivo de investigar a cidade e apontam a fraca capacidade de previsão de uma teoria de construção da cidade. No entanto, a própria capacidade de previsão da investigação positivista tem sido alvo de crítica, porque a natureza reducionista desta abordagem não tem sido eficaz no tratamento das questões relativas ao comportamento humano. Por outro lado, os grupos artísticos e literários desconfiam do enfoque único da morfologia urbana na realidade física da cidade. No entanto, a crítica relacionada com o que pode ser interpretado como o determinismo físico da morfologia urbana pode também ser silenciada: a morfologia urbana aborda a cidade não como um artefacto, mas como organismo, onde o mundo físico é inseparável dos processos de transformação a que está sujeito. O enfoque está no mundo físico enquanto 'resultado' de forças sociais e económicas com uma natureza dinâmica. $\mathrm{O}$ desafio do ISUF é demonstrar os processos correntes que suportam o modo como as cidades são construídas e transformadas, definir e ilustrar os princípios de transformação em diferentes contextos - por exemplo, como é que os quarteirões são alterados, dependendo de como são implantados numa fase inicial e do tipo e da intensidade de desenvolvimento em seu redor; ou como diferentes condições definirão se uma determinada área é sujeita a um desenvolvimento de densificação ou a um completo re-desenvolvimento.

Segundo, o material de investigação que o ISUF oferece a este mundo agora mais alargado tem as suas próprias fragilidades. Uma parte significativa da investigação em morfologia urbana tem-se centrado em cidades Europeias históricas, uma dupla limitação que pode parecer dificultar aplicações práticas no mundo atual. Existe uma necessidade de a investigação abordar a expansão sem precedentes das cidades ao longo deste século, e uma necessidade de dirigir esta investigação para cidades que cresceram em culturas não-Europeias. Significativamente, no entanto, um conjunto de estudos recentes sobre as cidades do 
século XX na Europa, América do Norte e Austrália, bem como sobre um número crescente de cidades Asiáticas, confirma a validade dos princípios de construção da cidade identificados anteriormente pelas três escolas: os elementos básicos da forma urbana são os mesmos, e os processos de formação e transformação partilham a mesma base. Esta é a parte emocionante e abrangente da morfologia urbana: o seu potencial para ajudar a enfrentar o boom de construção da cidade das próximas décadas noutras áreas para além da América do Norte e da Europa.

De grande importância em relação a esta e a outras tarefas é o facto de a revolução em curso no modo como se registam as atividades de construção da cidade constituir uma grande promessa para a análise morfológica. Os Sistemas de Informação Geográfica (SIG) podem agora, não apenas registar as características espaciais dos habitats mas também, ligar atributos espaciais a dados quantitativos de modo a que, pela primeira vez, o espaço físico possa ser medido e analisado em relação às forças socioeconómicas que o moldam - por exemplo, dados dos censos podem agora ser ligados, com bastante facilidade, às formas construídas e aos usos de solo. Para além disso, muitas unidades administrativas recolhem os seus registos ao nível da parcela de solo individual, permitindo assim uma análise urbana à escala de trabalho privilegiada pelos morfologistas. Como resultado, estes novos mapas 'inteligentes' permitem análises regionais desenvolvidas com dados detalhados, disponíveis ao nível da parcela, ou inversamente, análises ao nível da parcela podem ser aplicadas a toda uma região. Esta possibilidade tem enormes implicações, tanto para a investigação como para a gestão de áreas urbanizadas. Significativamente, os SIG baseados na parcela oferecem os dados empíricos que os morfologistas necessitam (e que até agora adquiriam meticulosamente de forma manual). Recolhidos de modo longitudinal, estes dados empíricos abrem imensas oportunidades de investigação para monitorizar e explicar a transformação das formas urbanas. Para além disso, os SIG baseados na parcela combinam dados que são úteis às indústrias de construção e do imobiliário bem como aos planeadores urbanos e aos decisores políticos. Eles oferecem a capacidade de coordenar as atividades destes campos tradicionalmente separados. Por último, e talvez mais importante, estas bases de dados espacialmente codificadas permitem aos morfologistas estudar, pela primeira vez, vastas áreas de desenvolvimento urbano ou suburbano. Pela primeira vez, a análise em morfologia urbana tem os instrumentos para abordar as áreas metropolitanas contemporâneas.

As expectativas devem necessariamente ser cautelosas - a tecnologia demonstrou ser um 'excelente servo, mas um pobre mestre'. No entanto, os atuais avanços nos SIG baseados na parcela podem ajudar a mover o centro da investigação em morfologia urbana da sua fundação no estudo de pequenas cidades históricas até às grandes regiões urbanizadas da atualidade, e de aplicações em conservação urbana e património até à gestão do desenvolvimento urbano futuro. Certamente, as oportunidades para a construção de teoria que o ISUF oferece pode tornar este num futuro tangível.

\section{Referências}

Conzen, M. R. G. (1960) Alnwick, Northumberland: a study in town-plan analysis, Institute of British Geographers Publication 27 (George Philip, Londres).

Lévi-Strauss, C. (1955) Tristes Tropiques (Terre Humaine, Paris).

Muratori, S. (1959) Studi per una operante storia urbana di Venezia (Istituto Poligraphico dello Stato, Roma).

Muratori, S., Bollati, R., Bollati, S. e Marinucci, G. (1963) Studi per una operante storia urbana di Roma (Consiglio Nazionale delle Riceche, Roma).

\section{Notas}

i Para uma lista de referências sobre o trabalho das três escolas ver Moudon, A. V. (1994) 'Getting to know the built landscape: typomorphology', em Franck, K. A. e Schneekloth, L. (eds.) Ordering space: types in architecture and design (Van Nostrand Reinhold, Nova Iorque) 289-311. 
ii Para uma discussão sobre o papel da morfologia urbana na geografia, e referências sobre este papel, ver Conzen, M. P. (1978) 'Analytical approaches to the urban landscape', em Butzer, K. W. (ed.) Dimensions of human geography, University of Chicago Department of Geography Research Paper 186, 128-65; Slater, T. R. (ed.) (1990) The built form of Western cities (Leicester University Press, Leicester); Whitehand, J. W. R. (ed.) (1981) The urban landscape: historical development and management Institute of British Geographers Special Publication 13 (Academic Press, Nova Iorque); Whitehand, J. W. R. (1988) 'Recent developments in urban morphology', em Denecke, D. and Shaw, G. (eds) Urban historical geography: recent progress in Britain and Germany (Cambridge University Press, Cambridge) 285-96.

iii Para uma discussão sobre o papel da morfologia urbana no desenho urbano e na arquitetura, e respetivas referências, ver Panerai, P., Depaule, J. C., Demorgon, M. e Veyrenche, M. (1980) Eléments d'analyse urbaine (Editions Archives d'Architecture Moderne, Bruxelas); Moudon, A. V. (1992) 'A catholic approach to organizing what urban designers should know', Journal of Planning Literature 6, 331-49.

\section{Notas de tradução}

a M. R. G. Conzen (1907-2000) faleceu a 4 de Fevereiro de 2000.

e A publicação da Escola de Versalhes Castex, J., Depaule, J. C. e Panerai, P. (1970) Formes urbaines: De l'îlot à la barre de (Dunod, Paris) foi entretanto adaptada e traduzida para Inglês Panerai, P., Castex, J., Depaule, J.-C. e Samuels, I. (2004) Urban forms, the death and life of the urban block (Architectural Press, Oxford).

\title{
Tradução do título, resumo e palavras-chave
}

Urban morphology as an emerging interdisciplinary field

\begin{abstract}
The forces and events leading to the formation of the International Seminar on Urban Form (ISUF) are identified. ISUF is expanding the field of urban morphology beyond its original confines in geography, particularly into the domains of architecture and planning. Three schools of urban morphology, in England, Italy and France, are coming together, following seminal work by two morphologists, M. R. G. Conzen and Saverio Muratori. The bringing together of these schools provides the basis for an interdisciplinary field and the opportunity to establish common theoretical foundations for the growing number of urban morphologists in many parts of the world. ISUF's ambitious mission is to address real and timely issues concerning city building by providing a forum for thought and action which includes related disciplines and professions in different cultures. The potential of an interdisciplinary urban morphology to contribute to the understanding and management of urban development in a period of unprecedented change is discussed.
\end{abstract}

Keywords: urban morphology, interdisciplinarity, city building, geography, architecture

\section{Tradução}

Este texto foi traduzido por Vítor Oliveira, que agradece a Anne Vernez Moudon a disponibilidade permanente para esclarecer todas as questões relacionadas com este processo.

\section{$22^{\text {nd }}$ International Seminar on Urban Form}

A cidade de Roma, e em particular a Facoltà di Architettura Sapienza, acolherá no próximo mês de Setembro o $22^{\circ}$ International Seminar on Urban Form. Entre os dias 22 e 26, cerca de duas centenas de participantes irão discutir a 'cidade enquanto organismo' e desenhar 'novas visões para a vida urbana', num debate estruturado nas quatro escalas da escola Italiana.

As excursões pós-conferência incluem visitas a 'Roma Moderna e Contemporânea', à Villa
Adriana e Villa D'Este, e à cidade histórica de Todi. A Comissão Científica da conferência inclui: Giancarlo Cataldi (Università degli Studi di Firenze), Michael Conzen (University of Chicago), Kai Gu (University of Auckland), Ivor Samuels (University of Birmingham), JeanFrançois Lejeune (University of Miami), Vítor Oliveira (Universidade do Porto), Piero Ositilio Rossi (Sapienza Università di Roma) e Jeremy Whitehand (University of Birmingham). 